\title{
Processing factors that influence casein and serum protein separation by microfiltration ${ }^{1}$
}

\author{
E. Hurt and D. M. Barbano ${ }^{2}$ \\ Northeast Dairy Foods Research Center, Department of Food Science, Cornell University, Ithaca, NY 14853
}

\begin{abstract}
Our objective was to demonstrate the effect of various processing factors on the performance of a microfiltration system designed to process skim milk and separate casein $(\mathrm{CN})$ from serum proteins $(\mathrm{SP})$. A mathematical model of a skim milk microfiltration process was developed with 3 stages plus an additional fourth finishing stage to standardize the retentate to $9 \%$ true protein (TP) and allow calculation of yield of a liquid 9\% TP micellar CN concentrate (MCC) and milk SP isolate (MSPI; 90\% SP on a dry basis). The model was used to predict the effect of 5 factors: 1 ) skim milk composition, 2) heat treatment of skim milk, 3) concentration factor $(\mathrm{CF})$ and diafiltration factor (DF), 4) control of $\mathrm{CF}$ and $\mathrm{DF}$, and 5) SP rejection by the membrane on retentate and permeate composition, SP removal, and MCC and MSPI yield. When skim milk TP concentration increased from 3.2 to $3.8 \%$, the $\mathrm{TP}$ concentration in the third stage retentate increased from 7.92 to $9.40 \%$, the yield of MCC from 1,000 kg of skim milk increased from 293 to $348 \mathrm{~kg}$, and the yield of MSPI increased from 6.24 to $7.38 \mathrm{~kg}$. Increased heat treatment $\left(72.9\right.$ to $\left.85.2^{\circ} \mathrm{C}\right)$ of skim milk caused the apparent $\mathrm{CN}$ as a percentage of TP content of skim milk as measured by Kjeldahl analysis to increase from 81.97 to $85.94 \%$ and the yield of MSPI decreased from 6.24 to $4.86 \mathrm{~kg}$, whereas the third stage cumulative percentage SP removal decreased from 96.96 to $70.08 \%$. A CF and $\mathrm{DF}$ of $2 \times$ gave a third stage retentate $\mathrm{TP}$ concentration of $5.38 \%$ compared with $13.13 \%$ for a $\mathrm{CF}$ and $\mathrm{DF}$ of $5 \times$, with the third stage cumulative SP removal increasing from 88.66 to $99.47 \%$. Variation in control of the balance between CF and DF (instead of an equal $\mathrm{CF}$ and $\mathrm{DF}$ ) caused either a progressive increase or decrease in $\mathrm{TP}$ concentration in the retentate across

\footnotetext{
Received January 30, 2010.

Accepted June 1, 2010.

${ }^{1}$ Use of names, names of ingredients, and identification of specific

${ }^{2}$ Corresponding author: dmb37@cornell.edu
} models of equipment is for scientific clarity and does not constitute any endorsement of product by authors, Cornell University, or the Northeast Dairy Foods Research Center.
\end{abstract}

stages depending on whether $\mathrm{CF}$ was greater than $\mathrm{DF}$ (increasing $\mathrm{TP}$ in retentate) or $\mathrm{CF}$ was less than $\mathrm{DF}$ (decreasing TP in retentate). An increased rejection of SP by the membrane from an SP removal factor of 1 to 0.6 caused a reduction in MSPI yield from 6.24 to 5.19 $\mathrm{kg} / 1,000 \mathrm{~kg}$ of skim milk, and third stage cumulative SP removal decreased from 96.96 to $79.74 \%$. Within the ranges of the 5 factors studied, the TP content of the third stage retentate was most strongly affected by the target $\mathrm{CF}$ and DF and variation in skim milk composition. Cumulative percentage SP removal was most strongly affected by the heat treatment of skim milk, the SP removal factor, and the target $\mathrm{CF}$ and $\mathrm{DF}$. The MCC yield was most strongly affected by initial skim milk composition. Yield of MSPI was strongly affected by skim milk composition, whereas the heat treatment of milk and SP removal factor also had a large effect. Key words: microfiltration, serum protein, micellar casein concentrate

\section{INTRODUCTION}

Microfiltration (MF) can be used to fractionate skim milk into a micellar CN concentrate (MCC) and milk serum protein isolate (MSPI). Skim milk can be processed with an MF system, which retains $\mathrm{CN}$ and allows serum proteins (SP) to pass through the membrane. A 1-stage system will remove only a portion of the SP from the skim milk. If higher levels of SP removal from the MCC are desired, then additional MF diafiltration stages are required, with dilution of the retentate from the previous stage with water or UF permeate (Nelson and Barbano, 2005) for diafiltration. Papadatos et al. (2002, 2003) found that, in 30 of 36 mo using prevailing price conditions in the United States for the period 1998 to 2000, the use of a skim milk MF retentate increased net revenues for the production of Cheddar and low-moisture part skim Mozzarella compared with conventional cheesemaking. The MCC could also have applications outside cheesemaking in a variety of dairy and nondairy beverage and food applications. The SP purified from skim milk has enhanced functionality when compared with similar products made from cheese whey (Britten and Pouliot, 1996). 
Whether on a research or industrial scale, efficient production of retentate and permeate products at target composition will be important. Multiple factors influence both the composition of MCC and the SP removal efficiency of the MF system. These factors include the initial skim milk composition, the heat treatment history of the skim milk, the concentration factor (CF) used for each stage of the MF, the control of the CF and diafiltration factors (DF), and the SP rejection characteristics of the membrane used in the MF process.

Milk composition can vary because of breed, genetics, nutrition, season, stage of lactation, and health status of the cow (Laben, 1963). A milk processing plant will experience variation in incoming milk composition. Regional and seasonal variations in milk composition can be large (Barbano, 1990). This variation in milk composition would cause variation in the composition of MF retentates and permeates unless other processing steps (e.g., ultrafiltration) are taken to protein standardize the skim milk before MF (Quiñones et al., 1997, 1998).

The temperature and time of heat treatment of skim milk are other factors that can influence the performance of separating $\mathrm{CN}$ and $\mathrm{SP}$ in an MF process of skim milk. Heat treatment of milk is known to cause $\beta$-LG to form disulfide bonds with $\kappa$ - $\mathrm{CN}$ on the surface of CN micelles (Sawyer, 1969). This causes an increase in the size of $\mathrm{CN}$ micelles and an apparent increase in $\mathrm{CN}$ as a percentage of true protein (TP; CN\% $\mathbf{T P}$ ) as measured by Kjeldahl (Lynch et al., 1998). The $\beta$-LG bound to the micelles is incorrectly counted as CN in the Rowland based fractionation (Rowland, 1937) Kjeldahl noncasein nitrogen method (method number 998.05; 33.2.64; AOAC, 2000). However, the increase in measured CN\%TP in milk as a function of increasing heat treatment is a useful quantitative index of the extent of heat denaturation of SP. Casein-bound $\beta$-LG attributed to heat-induced interactions cannot pass through an MF membrane, and this will reduce the yield of MSPI. Ma et al. (2000) reported that CN as a percentage of $\mathrm{CP}$ in commercial samples of fluid milk pasteurized with temperatures ranging from 76 to $80^{\circ} \mathrm{C}$ and holding times from 20 to $30 \mathrm{~s}$ increased $2.81 \%$ to $5.56 \%$ over the level in raw milk because of pasteurization, with an average increase of $3.79 \%$. Therefore, pasteurization of skim milk before MF may reduce the removal of SP proteins.

The target $\mathrm{CF}$ will influence the performance of the MF system. The higher the CF, the higher the SP removal for each stage, possibly resulting in fewer stages. However, there will be practical limits to the extent that $\mathrm{CF}$ can be increased. As CF increases, the concentration of $\mathrm{CN}$ in the retentate will increase and at some point the viscosity of the retentate at the membrane surface will be such that the membranes will foul extensively, reducing permeate and SP removal. Vadi and Rizvi (2001) reported that as skim milk was concentrated by $\mathrm{MF}$, the apparent viscosity of the retentate at $50^{\circ} \mathrm{C}$ increased from less than $2 \mathrm{cP}$ for skim milk to approximately $3 \mathrm{cP}$ for $4 \times$ retentate. Whereas the target $\mathrm{CF}$ and $\mathrm{DF}$ may both be $3 \times$, in practice there will be some variation in ability to achieve these targets. Variation or limitations in the ability of the system to accurately control CF and DF could also be a cause of variation in performance of an MF system and variation in product composition.

Different types of MF membranes (e.g., polymeric versus ceramic) could have different SP removal factors, which would affect end product compositions and yield of MSPI. A wide range of MF systems have been used to separate micellar CN from SP and there is also a wide range of reported removal (rejection) factors for SP. Nelson and Barbano (2005) found SP removal for $0.1-\mu \mathrm{m}$ ceramic uniform transmembrane pressure membranes was close to theoretical, indicating a removal factor close to 1. Zulewska et al. (2009) found an SP removal factor of 0.99 for a ceramic uniform transmembrane pressure system and 0.66 for a polymeric spiral wound system. The influence of the factors mentioned above is not well defined and their relative importance may not be clear to potential commercial users of MF technology for separation of CN and SP.

The objective of our research was to demonstrate how variation in skim milk composition, different heat treatments of skim milk (i.e., denaturation of SP), different target MF concentration factors, variation in control of MF $\mathrm{CF}$ and $\mathrm{DF}$, and differences in degree of SP removal by the membrane would be expected to influence the composition of retentate (MCC), permeate (i.e., SP yield), and SP removal when produced using a 3-stage MF process designed to separate $\mathrm{SP}$ from micellar CN.

\section{MATERIALS AND METHODS}

\section{Processing Factors Studied}

Five factors were explored in our study: 1) the effect of variation in skim milk composition reflecting withinday, between-day, or seasonal variation; 2) the effect of differing heat treatments of skim milk as they cause heat denaturation of SP, resulting in binding of SP to $\mathrm{CN}$ micelles; 3) the effect of the choice of different MF $\mathrm{CF}$ and DF; 4) the effect of lack of exact control of $\mathrm{CF}$ and DF, specifically, cases where $\mathrm{CF}$ does not equal DF; and 5) the effect of different SP retention factors by the MF membrane. For each of these 5 factors, the 
Table 1. Default skim milk composition and model inputs for component removal factors, concentration factors (CF), and diafiltration factors (DF)

\begin{tabular}{ll}
\hline Item & Value \\
\hline Skim milk composition (\% by weight) & \\
CN & 2.623 \\
Serum protein & 0.577 \\
Ash & 0.729 \\
NPN & 0.190 \\
Lactose & 4.850 \\
Model factor & \\
Removal factor & \\
Ash & 1 \\
Lactose & 1 \\
NPN & 1 \\
Serum protein & 1 \\
CN & 0 \\
CF & \\
Stage 1 & 3.0 \\
Stage 2 & 3.0 \\
Stage 3 & 3.0 \\
DF & \\
Stage 2 & 3.0 \\
Stage 3 & 3.0 \\
\hline
\end{tabular}

effect on retentate composition, permeate composition, and overall SP removal was calculated for each MF stage. Additionally, yields of MCC and MSPI were calculated, assuming that liquid MCC contained 9\% TP and that dried MSPI was $90 \%$ SP. These 5 factors are process control issues commonly encountered during MF processing of skim milk to create an SP-reduced MCC and an MSPI.

\section{Model Development}

A model was developed using Excel 2007 (Microsoft Corp., Redmond, WA) to calculate the composition of retentate and permeate produced in each stage of a 3-stage bleed-and-feed MF processing of skim milk. The model was independent of the type of MF system used and established theoretical values that should be achieved given well-defined assumptions. For each stage there was a feed, retentate, and permeate. Input and default values for model calculations are shown in Table 1. All concentrations are expressed as percentage on a weight basis. The $\mathrm{CF}$ is the ratio of feed mass to retentate mass. The DF is the sum of mass of water added and mass of retentate divided by mass of retentate, where the DF for each stage used the mass of retentate produced in the previous stage.

The solute removal factors, a required model input, are the ratio of the solute's concentration in the MF permeate to its concentration in the MF permeate portion of the feed. A removal factor of 1 would mean that the solute is not retained by the membrane. It was necessary to use the solute concentration in the MF permeate portion of skim milk because skim milk contains $\mathrm{CN}$ micelles and the dry mass of $\mathrm{CN}$ takes up a portion of the mass of skim milk. As a result, other soluble milk components exist in solution in the MF permeate portion of skim milk at a higher concentration than indicated by direct analysis of the skim milk. If a solute in the MF permeate portion of skim milk was not retained by the membrane, then its concentration in the MF permeate would be equal to its concentration in the permeate portion of the MF feed solution.

Assumptions. Several assumptions were made regarding the MF feed material and partitioning of milk components during MF. It was assumed that the initial skim milk had $0 \%$ fat. For each scenario, it was assumed that $100 \%$ of $\mathrm{CN}$ was rejected (i.e., concentration of $\mathrm{CN}$ in the permeate was $0 \%$ ). The ash in skim milk was calculated using the following empirical equation: ash $=0.0596 \times[\mathrm{TP}]+0.5379$ (Kaylegian et al., 2006). Approximately two-thirds of the calcium and phosphate content of milk was assumed to be bound to the CN micelles (Jenness, 1959).

Permeate Portion Calculations. The concentrations of SP, lactose, and NPN in the MF permeate portion were calculated as the mass of SP, lactose, and NPN divided by the mass of the permeate portion. The mass of the permeate portion in the feed solution was the total mass minus the mass of $\mathrm{CN}$ plus the mass of ash associated with the $\mathrm{CN}$ micelles. The equation for serum protein is $[\mathrm{SP}]_{\text {serumphase }}=[\mathrm{SP}]_{\text {bulk }} \times$ mass $_{\text {feed }} /$ $\left(\right.$ mass $_{\text {feed }}-$ mass $_{\text {feed }} \times[\mathrm{CN}]_{\text {feed }} / 100-$ mass $_{\text {skimmilk }} \times 2 / 3$ $\left.[a s h]_{\text {skimmilk }} / 100\right)$. The same equation was used for lactose and NPN, replacing the concentration of SP with the concentration of lactose or NPN.

The concentration of ash in the permeate portion for the initial MF feed was calculated as for SP, lactose, and NPN except that the ash not associated with the CN micelles was assumed to be one-third of the total ash. For subsequent stages the permeate portion ash in the feed was calculated as the remaining soluble ash divided by the mass of the permeate portion (the same denominator as the equation for SP shown above).

Composition Calculations for Retentate, Permeate, and Feed. The concentration of SP, lactose, NPN, and ash in the MF permeate was calculated as their concentration in the permeate portion of the feed times the removal factor. The concentration of $\mathrm{CN}$ in permeate was assumed to be $0 \%$. The concentration of $\mathrm{CN}, \mathrm{SP}, \mathrm{NPN}$, lactose, and ash in the retentate was calculated as the mass of each milk component in the feed minus its mass in the permeate, with the difference divided by the total mass of retentate. This equation can also be expressed in terms of $\mathrm{CF}$ for each: $[\mathrm{SP}]_{\text {retentate }}=\mathrm{CF} \times[\mathrm{SP}]_{\text {feed }}-(\mathrm{CF}-1) \times[\mathrm{SP}]_{\text {permeate }}$.

The feed for the first stage was skim milk, with the default composition, model factors for component re- 
moval, and $\mathrm{CF}$ and DF values shown in Table 1. For the second and third stages, the feed composition was calculated from the retentate composition of the previous stage and the DF as follows for SP in the second stage: $[\mathrm{SP}]_{\text {feedstage2 }}=[\mathrm{SP}]_{\text {retentatestage } 1} / \mathrm{DF}_{\text {stage2 } 2}$. True protein concentration in the feed was calculated as the sum of the SP and CN concentrations.

Cumulative SP Removal Calculation. The cumulative SP removal for each stage was calculated as the mass of SP in the skim milk minus the mass of SP remaining in the retentate, with this sum divided by the mass of SP in the skim milk and the total multiplied by 100. In terms of $\mathrm{CF}$, the above reduces to equations for each stage shown below:

$$
\begin{gathered}
\text { Stage 1: \% removal }=100 \times \\
{\left[1-[\mathrm{SP}]_{\text {retentate }} /\left([\mathrm{SP}]_{\text {milk }} \times \mathrm{CF}_{\text {stagel }}\right)\right]}
\end{gathered}
$$

Stage $2: \%$ removal $=100 \times\left[1-\left([\mathrm{SP}]_{\text {retentate }} /[\mathrm{SP}]_{\text {milk }}\right)\right.$

$$
\left.\times \mathrm{DF}_{\text {stage } 2} /\left(\mathrm{CF}_{\text {stage } 1} \times \mathrm{CF}_{\text {stage } 2}\right)\right]
$$

Stage 3: \% removal $=100 \times\left[1-\left([\mathrm{SP}]_{\text {retentate }} /[\mathrm{SP}]_{\text {milk }}\right)\right.$ $\left.\times\left(\mathrm{DF}_{\text {stage } 2} \times \mathrm{DF}_{\text {stage } 3}\right) /\left(\mathrm{CF}_{\text {stage } 1} \times \mathrm{CF}_{\text {stage } 2} \times \mathrm{CF}_{\text {stage } 3}\right)\right]$

Yield of MCC and MSPI. The processing end products were assumed to be a liquid MCC with $9 \%$ TP and a dried MSPI containing 90\% SP. A finishing fourth MF stage would be required in most cases to bring the TP content of the retentate to $9 \%$. If after the third stage the retentate TP was greater than $9 \%$, then water would be added to bring the TP concentration down to $9 \%$. A basis of $1,000 \mathrm{~kg}$ of starting skim milk was used to calculate theoretical yield and the fourth stage was an MF stage with the same removal factors as earlier stages. There was no water added to the retentate at the start of the fourth stage, but the calculations for concentration in permeate and retentate were the same as for earlier stages (DF equaled 1). The amount of permeate to be removed in the fourth stage was found by iteration to achieve $9 \% \mathrm{TP}$ in the retentate. The yield of MSPI includes SP removed in the fourth finishing MF stage.

\section{Definition of Parameters Studied}

Influence of Skim Milk Composition. Four different skim milk compositions were used for estimating the effects of variation in milk composition on MF (Table 2). The model factors were kept constant and were the default factors shown in Table 1. Four concentrations of TP were chosen, with CN\%TP kept
Table 2. Different skim milk compositions (\% by weight) used to determine the effect of variation in skim milk composition on microfiltration performance

\begin{tabular}{lcccc}
\hline $\begin{array}{l}\text { Milk } \\
\text { component }\end{array}$ & \multicolumn{5}{c}{$\%$ by weight } \\
\hline True protein & 3.200 & 3.400 & 3.600 & 3.800 \\
CN & 2.623 & 2.787 & 2.951 & 3.115 \\
Serum protein & 0.577 & 0.613 & 0.649 & 0.685 \\
NPN & 0.190 & 0.190 & 0.190 & 0.190 \\
CN $\mathrm{TP}^{1}$ & 81.97 & 81.97 & 81.97 & 81.97 \\
Lactose & 4.850 & 4.850 & 4.850 & 4.850 \\
Ash & 0.729 & 0.741 & 0.752 & 0.764 \\
\hline
\end{tabular}

${ }^{1} \mathrm{CN} \% \mathrm{TP}=\mathrm{CN}$ as a percentage of true protein.

constant at $81.97 \%$. Ash content of each skim milk was calculated as described in Kaylegian et al. (2006). Lactose and NPN were assumed not to vary among the 4 milks. To determine the influence of skim milk composition on an MF process, several model outputs were calculated. The effect on retentate composition was determined by comparing the composition of the third stage retentates and the TP concentration in the retentates for each stage with different skim milks. The variation in SP content of the permeates from 3 stages and SP removal as skim milk composition changed was also determined. Finally, the yield of MCC and MSPI from $1,000 \mathrm{~kg}$ of skim milk with the 4 different TP levels was calculated.

Influence of Heat Treatment of Skim Milk. Heat treatment of skim milk increases the apparent CN\% TP as measured by Kjeldahl analysis because of $\beta-\mathrm{LG}$ and $\alpha$-LA binding to $\kappa-\mathrm{CN}$. A preliminary experiment was conducted with $2 \%$ fat milk to demonstrate the magnitude of change in $\mathrm{CN} \% \mathrm{TP}$ at various pasteurization temperatures at a constant holding time of $25 \mathrm{~s}$ in a tubular pasteurizer; these values were used to help define the range of CN\%TP used in the modeling. Raw milk was cold separated into cream and skim fractions with a separator (model 590, DeLaval, Poughkeepsie, NY) and

Table 3. Different skim milk compositions (\% by weight) used to determine the effect of different degrees of heat treatments (i.e., increased apparent $\mathrm{CN} \% \mathrm{TP}^{1}$ ) on microfiltration performance

\begin{tabular}{lcccc}
\hline $\begin{array}{l}\text { Milk } \\
\text { component }\end{array}$ & \multicolumn{5}{c}{ \% by weight } \\
\hline True protein & 3.2 & 3.2 & 3.2 & 3.2 \\
CN & 2.623 & 2.68 & 2.72 & 2.75 \\
Serum protein & 0.577 & 0.52 & 0.48 & 0.45 \\
NPN & 0.19 & 0.19 & 0.19 & 0.19 \\
CN\%TP & 81.97 & 83.75 & 85.00 & 85.94 \\
Lactose & 4.85 & 4.85 & 4.85 & 4.85 \\
Ash & 0.729 & 0.729 & 0.729 & 0.729 \\
\hline
\end{tabular}

${ }^{1}$ Apparent $\mathrm{CN} \% \mathrm{TP}=\mathrm{CN}$ as a percentage of true protein that would be expected as measured by Kjeldahl that increases as a result of serum protein being counted as if it were $\mathrm{CN}$. 
Table 4. Combinations of concentration factor (CF) and diafiltration factor (DF) used to determine the effect of variation in control of $\mathrm{CF}$ and $\mathrm{DF}$ on microfiltration performance

\begin{tabular}{cccccc}
\hline \multicolumn{5}{c}{ Combination } \\
\cline { 2 - 6 } Stage & CF 3.0 + DF 3.0 & CF 3.1 + DF 3.0 & CF 2.9 + DF 3.0 & CF 3.0 + DF 3.1 & CF 3.0 + DF 2.9 \\
\hline CF & 3.0 & 3.1 & 2.9 & 3.0 & 3.0 \\
1 & 3.0 & 3.1 & 2.9 & 3.0 & 3.0 \\
2 & 3.0 & 3.1 & 2.9 & 3.0 & 3.0 \\
3 & 3.0 & 3.0 & 3.0 & 3.1 & 2.9 \\
DF & 3.0 & 3.0 & 3.0 & 3.1 & 2.9 \\
2 & & & & & \\
3
\end{tabular}

then raw skim milk and cream were blended to make $2 \%$ fat milk. Approximately $18.9 \mathrm{~L}$ of $2 \%$ fat raw milk were added to a jacketed steam kettle, heated to $60^{\circ} \mathrm{C}$, and then homogenized with 2 passes through a 2-stage homogenizer (model 200 E, Gaulin APV, Everett, MA), with the first stage pressure set a $13,790 \mathrm{kPa}$ and the second stage at $3,448 \mathrm{kPa}$. After homogenization, the milk was pasteurized at approximately $72.9,77.2,79.9$, or $85.2^{\circ} \mathrm{C}$ for $25 \mathrm{~s}$ in a tubular pasteurizer, as described by Ma and Barbano (2003). Milk samples after heating and homogenization before pasteurization and after pasteurization were analyzed by the Kjeldahl method for TN (method number 991.20; 33.2.11; AOAC, 2000), noncasein nitrogen (method number 998.05; 33.2.64; AOAC, 2000), and NPN (method number 991.21; 33.2.12; AOAC, 2000).

The heat-induced binding of SP to $\mathrm{CN}$ micelles reduces the amount of SP that can be removed from skim milk. The model factors and the skim milk composition were the default factors shown in Table 1, except that the amounts of $\mathrm{CN}$ and $\mathrm{SP}$ were modified to give the different CN\% TP values shown in Table 3. To determine the influence of heat treatment of skim milk on $\mathrm{SP}$ removal by the MF process, the SP bound to $\mathrm{CN}$ in the MF retentates is presented as $\mathrm{SP}$ and the $\mathrm{CN}$ that would be seen by SDS PAGE, not as the "CN + heat denatured whey protein" that would be measured by using the Kjeldahl methods. The effect on third stage retentate composition and the $\mathrm{TP}$ concentration in the retentates for the individual stages with different CN\%TP in skim milk was determined. The variation in $\mathrm{SP}$ content in the MF permeates from 3 stages and SP removal as $\mathrm{CN} \% \mathrm{TP}$ in skim milk changed were calculated. Finally, the yields of MCC and MSPI from 1,000 $\mathrm{kg}$ of skim milk were determined.

Influence of $\boldsymbol{C F}$. The input skim milk composition and removal factors were kept constant as shown in Table 1. Paired CF and DF of 2,3,4, and $5 \times$ were used to estimate the effect of $\mathrm{CF}$ selection on $\mathrm{MF}$ performance. The influence of $\mathrm{CF}$ and $\mathrm{DF}$ was calculated for a 5-stage MF process with the same outputs calculated for retentates, permeates, and SP removal as for the influence of skim milk composition. Final yields of MCC and MSPI were not calculated because at 5 stages the yield would not be comparable to other calculated yields in this paper and with the retentates standardized to $9 \% \mathrm{TP}$, the MCC yields would be almost identical among the different $\mathrm{CF}$.

Influence of Variation in Control of CF and $\boldsymbol{D F}$. The input skim milk composition and removal factors were kept constant as shown in Table 1. The combinations of CF and DF used are shown in Table 4. In practice it would be difficult to exactly control CF and DF in real time during processing and they could vary within and between days, causing variation in composition of retentates and permeates. The influence of variation in control of $\mathrm{CF}$ and $\mathrm{DF}$ was calculated for a 3-stage MF process with the same outputs determined for retentates, permeates, and SP removal as were determined for the influence of skim milk composition.

Influence of SP Rejection by the Membrane. The input skim milk composition and the default model factors were kept constant, as shown in Table 1, except the SP removal factor was changed from 1 to 0.6. A removal factor of 0.6 corresponds to a classical rejection coefficient of 0.65 ( 1 minus the concentration of SP in

Table 5. Composition of retentate (\% by weight) produced in the third stage of a $3 \times$ microfiltration process with water diafiltration (stages 2 and 3) with different true protein (TP) levels in the starting skim milk, with model factors from Table 1 and skim milk compositions from Table 2

\begin{tabular}{lcccc}
\hline & \multicolumn{4}{c}{ TP in skim milk (\% by weight) } \\
\cline { 2 - 5 } Milk & 3.2 & 3.4 & 3.6 & 3.8 \\
\hline TP & 7.9215 & 8.4159 & 8.9101 & 9.4046 \\
CN & 7.8690 & 8.3607 & 8.8524 & 9.3444 \\
Serum protein & 0.0525 & 0.0552 & 0.0577 & 0.0602 \\
NPN & 0.0173 & 0.0171 & 0.0169 & 0.0167 \\
CN\%TP ${ }^{1}$ & 99.34 & 99.34 & 99.35 & 99.36 \\
Lactose & 0.4417 & 0.4365 & 0.4313 & 0.4262 \\
Ash & 1.4583 & 1.4806 & 1.5028 & 1.5251 \\
\hline
\end{tabular}

${ }^{1} \mathrm{CN} \% \mathrm{TP}=\mathrm{CN}$ as a percentage of $\mathrm{TP}$. 


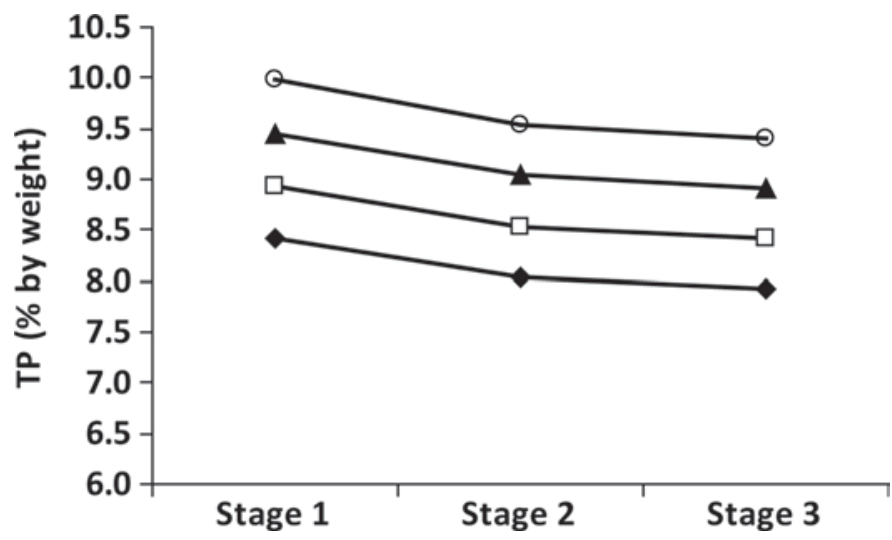

Figure 1. The effect of variation in true protein (TP) content of skim milk on the TP concentration in the retentate in each stage of a 3 -stage microfiltration process with water diafiltration (stages 2 and 3 ), with the model factors from Table 1 and the skim milk compositions from Table 2. : $3.2 \%$ TP; $\square: 3.4 \%$ TP; $\mathbf{\Delta}: 3.6 \%$ TP; $\bigcirc: 3.8 \%$ TP.

the permeate divided by the concentration of SP in the retentate). The influence of $\mathrm{CF}$ and $\mathrm{DF}$ was calculated for a 3-stage MF process with the same outputs for retentates, permeates, and SP removal that were used to determine the influence of skim milk composition. In addition, third stage cumulative SP removal as a function of SP rejection was plotted for each stage.

\section{RESULTS}

\section{Influence of Skim Milk Composition}

Retentate. The protein content of skim milk to be processed by MF may vary within and between days in a typical milk processing factory. The TP concentration in the retentate for each stage of MF increased as TP content of skim milk increased (Figure 1). The TP content of the MF retentate for each of 3 stages as a function of TP content of skim milk can be predicted by using the following 3 linear equations when the model factors in Table 1 were applied: stage $1: \mathrm{TP}_{\text {retentate }}=$ $2.601 \times \mathrm{TP}_{\text {skim milk }}+0.0859$; stage $2: \mathrm{TP}_{\text {retentate }}=2.4898$ $\times \mathrm{TP}_{\text {skim milk }}+0.0701$; stage $3: \mathrm{TP}_{\text {retentate }}=2.4578 \times$ $\mathrm{TP}_{\text {skim milk }}+0.00566$. These equations could be used in a factory to provide a point of reference on expected protein content of MF retentate from each stage when the protein content of skim milk varies. The expected compositions of final MF retentates produced from milks with 4 different TP contents are shown in Table 5 using the assumptions in Table 1 and the milk compositions in Table 2. The TP and CN content of the final third stage retentates increased with increasing TP content of the starting skim milk. The increase in $\mathrm{CN}$ content is expected to increase retentate viscosity, as reported by Vadi and Rizvi (2001). Increasing CN

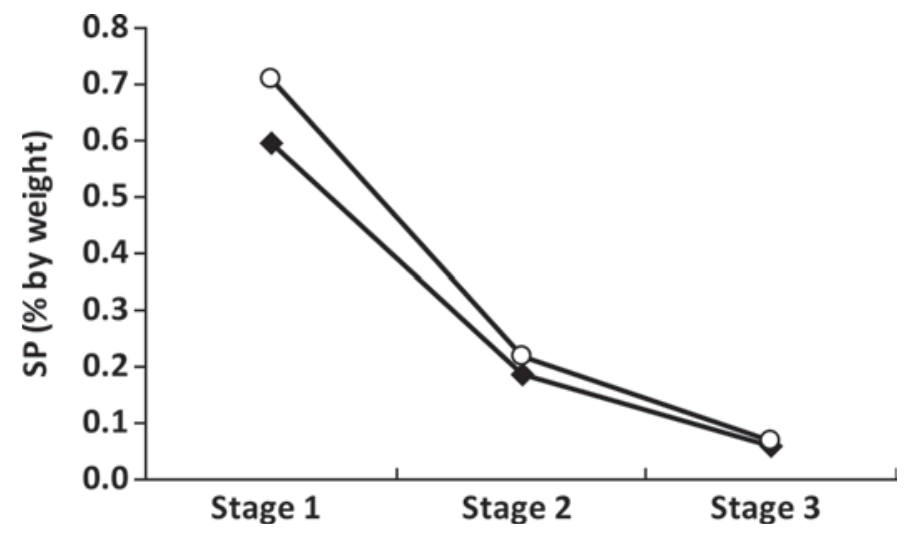

Figure 2. The effect of variation in true protein content of skim milk on serum protein (SP) concentration in the permeate in each stage of a 3-stage microfiltration process with water diafiltation (stages 2 and 3), with the model factors from Table 1 and the skim milk compositions from Table 2. : $3.2 \%$ TP; $\bigcirc: 3.8 \%$ TP.

content of the MF retentate may increase concentration polarization-driven fouling of the MF system. From a practical perspective, the $\mathrm{SP}, \mathrm{CN} \% \mathrm{TP}$, lactose, and NPN contents of the third stage MF retentate are not influenced by variation in the TP content of the starting skim milk (Table 5). Ash concentration in the third stage MF retentate increased with increasing TP in the skim milk (Table 5) as expected because CN concentration in the third stage MF retentate increased and the $\mathrm{CN}$ carried bound minerals with it.

Permeate. Higher TP concentration in the skim milk (Table 2) led to a higher concentration of SP in the MF permeates from each stage (Figure 2). This was attributed to the higher SP concentration in the skim milk (Table 2) and higher concentration of SP in the permeate portion of MF feed when the skim milk had higher TP concentrations. Irrespective of starting skim milk TP, there was a large decrease in SP in the permeate between stages 1 and 2 (Figure 2). A large amount of SP was removed in the first stage, and when the first stage MF retentate was diluted with water for diafiltration, the concentration of SP remaining in the permeate portion of the second stage feed and the re-

Table 6. Effect of skim milk composition on cumulative serum protein removal $(\%)$ in a 3 -stage $3 \times$ microfiltration $(\mathrm{MF})$ process with water diafiltration (stages 2 and 3 ) using the model factors from Table 1 and the skim milk compositions from Table 2

\begin{tabular}{lllll}
\hline & \multicolumn{4}{c}{ True protein in skim milk (\% by weight) } \\
\cline { 2 - 5 } MF stage & 3.2 & 3.4 & 3.6 & 3.8 \\
\hline 1 & 68.80 & 68.93 & 69.05 & 69.17 \\
2 & 90.27 & 90.35 & 90.42 & 90.49 \\
3 & 96.96 & 97.00 & 97.03 & 97.07 \\
\hline
\end{tabular}


Table 7. Effect of variation of skim milk composition on true protein (TP) content of the third stage retentate, yield of liquid micellar $\mathrm{CN}$ concentrate (MCC) standardized to $9 \% \mathrm{TP}$ with a fourth stage finishing step, dry solids yield of milk serum protein isolate (MSPI), and total percentage serum protein (SP) removal for a 3 -stage $3 \times$ microfiltration process with water diafiltration (stages 2 and 3 ), with 1,000 $\mathrm{kg}$ of the different skim milk compositions from Table 2

\begin{tabular}{lcccc}
\hline & \multicolumn{3}{c}{ TP in skim milk (\% by weight) } \\
\cline { 2 - 5 } Item & 3.2 & 3.4 & 3.6 & 3.8 \\
\hline Skim milk (kg) & 1,000 & 1,000 & 1,000 & 1,000 \\
Third stage TP (\% by weight) & 7.92 & 8.42 & 8.91 & 9.40 \\
Fourth stage permeate to remove (kg) & 40.22 & 21.78 & 3.37 & -15.09 \\
Yield liquid MCC, 9\% TP (kg) & 293 & 312 & 330 & 348 \\
Yield dry MSPI, 90\% (kg) & 6.24 & 6.62 & 7.00 & 7.38 \\
Total SP removal (\%) & 97.36 & 97.21 & 97.07 & 96.92 \\
\hline
\end{tabular}

sulting MF permeate for the second stage was reduced greatly.

SP Removal. Cumulative SP removal by MF increased gradually as TP content of the skim milk increased (Table 6), but the change was very small. Skim milk with a higher concentration of TP also had a higher concentration of SP and CN (Table 2). The higher concentration of SP in the skim milk did not affect cumulative SP removal, but the higher CN content of the skim milk did affect cumulative SP removal by increasing the concentration of SP in the permeate portion of the MF feed.

MCC and MSPI Yield. The yields of MCC and MSPI were expected to increase with increasing concentrations of $\mathrm{CN}$ and SP, respectively, in the milk, and they did (Table 7). The goal of the MF process was to produce an MCC that contained $9 \%$ TP. The $\mathrm{TP}$ content of the final third stage retentate was lower than $9 \%$ for starting skim milk TP of 3.2, 3.4, and $3.6 \%$; therefore, a fourth stage was required to remove additional permeate to achieve the final target concentration of $9 \% \mathrm{TP}$ in the MCC. The final TP content of the third stage retentate (i.e., MCC) was higher than $9 \%$ TP when starting with a skim milk containing $3.8 \%$ $\mathrm{TP}$, and a fourth stage was not required (Table 7 ). The liquid yield of MCC from skim milk containing 3.8\% TP was incrementally higher because the third stage retentate protein content had to be standardized down by the addition of water (Table 7). The 3 lower levels of $\mathrm{TP}$ in the skim milk required more permeate removal in a fourth stage MF finishing step to produce an MCC with $9 \%$ TP. The result resulting yield of MCC was lower because there was less TP in the skim milk (Table 7). The total SP removal from MCC in Table 7 was slightly higher when the starting skim milk had lower TP because more permeate (which contains SP) had to be removed in the fourth finishing stage to increase the TP in the MCC to $9 \%$.

Whereas the TP concentration of skim milk affected the SP removal and lactose, NPN, and ash contents of the retentates produced during MF, the main effect of different skim milk composition was on the TP content of the retentates produced by MF and yield of MCC and MSPI (Table 7). In addition to yield, lower TP concentration in skim milk required more processing to produce the desired liquid MCC containing 9\% TP. If a $9 \%$ protein standardized MCC product needed to be produced, then the protein content of the skim milk would have to be increased (possibly by UF) before $\mathrm{MF}$, the $\mathrm{CF}$ and $\mathrm{DF}$ of the MF process would have to be adjusted in response to changing incoming skim milk composition, or an extra filtration finishing step would be required.

\section{Influence of Heat Treatment of Skim Milk}

Selection of the time and temperature of heat treatment of skim milk before MF may influence the ability of the process to remove SP from skim milk. A preliminary experiment demonstrated that the CN\%TP (measured using Kjeldahl analysis) increased as the

Table 8. Composition of retentate (\% by weight) produced in the third stage of a $3 \times$ microfiltration process with water diafiltration (stage 2 and 3), where initial skim milk contained $3.2 \%$ true protein (TP) and skim milk had different levels of heat treatment that caused apparent CN\% TP to increase

\begin{tabular}{lcccc}
\hline & \multicolumn{4}{c}{ CN (\% TP in skim milk; Kjeldahl) } \\
\cline { 2 - 5 } Milk component & 81.97 & $83.75^{1}$ & $85.00^{1}$ & $85.94^{1}$ \\
\hline TP & 7.9215 & 8.0871 & 8.2034 & 8.2906 \\
CN & 7.8690 & 7.869 & 7.869 & 7.869 \\
Serum protein & 0.0525 & 0.2272 & 0.3434 & 0.4306 \\
NPN & 0.0173 & 0.0172 & 0.0172 & 0.0172 \\
CN\%TP & 99.34 & 97.30 & 95.92 & 94.91 \\
Lactose & 0.4417 & 0.4399 & 0.4387 & 0.4387 \\
Ash & 1.4583 & 1.4578 & 1.4578 & 1.4578 \\
\hline
\end{tabular}

${ }^{1}$ Estimated higher $\mathrm{CN}$ as a percentage of $\mathrm{TP}$ caused by heat treatment.

${ }^{2} \mathrm{CN} \% \mathrm{TP}=\mathrm{CN}$ as a percentage of $\mathrm{TP}$ in the retentate was calculated to not include heat-denatured serum protein. 


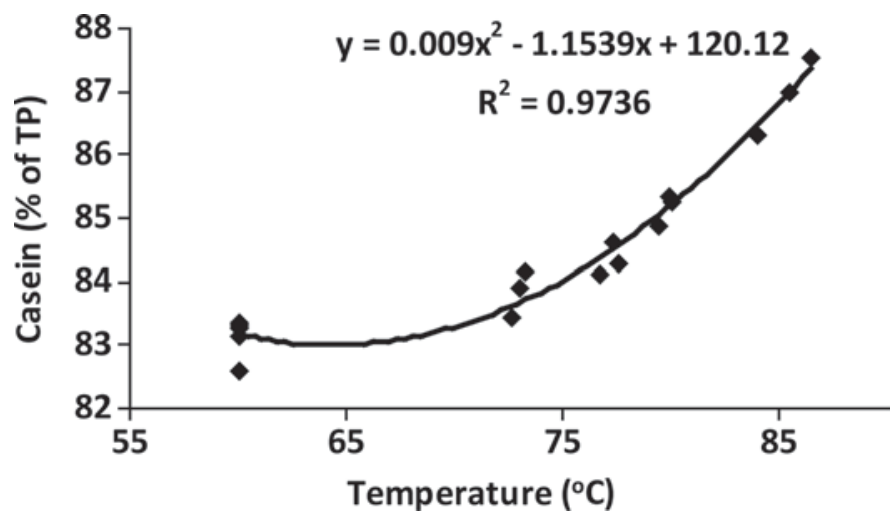

Figure 3. Casein as a percentage of true protein (TP; as measured by Kjeldahl analysis) as a function of pasteurization temperature with a hold time of $25 \mathrm{~s}$.

temperature of pasteurization increased (Figure 3) because of denaturation and binding of SP to CN micelles. The SP that was bound to $\mathrm{CN}$ micelles will not pass through an MF membrane into the permeate and will be expected to decrease the yield of removed SP. However, the removal factor for the SP not bound to $\mathrm{CN}$ should be unchanged. A quadratic equation fits the observed data well (Figure 3), with a coefficient of determination of 0.974. A hypothetical increase in CN\%TP with increasing temperature of pasteurization (as shown in Table 3) means that the concentration of SP soluble in the permeate portion of the skim milk will decrease (Table 3) and thus it would be expected that the removal of SP from skim milk will decrease with increasing heat treatment.

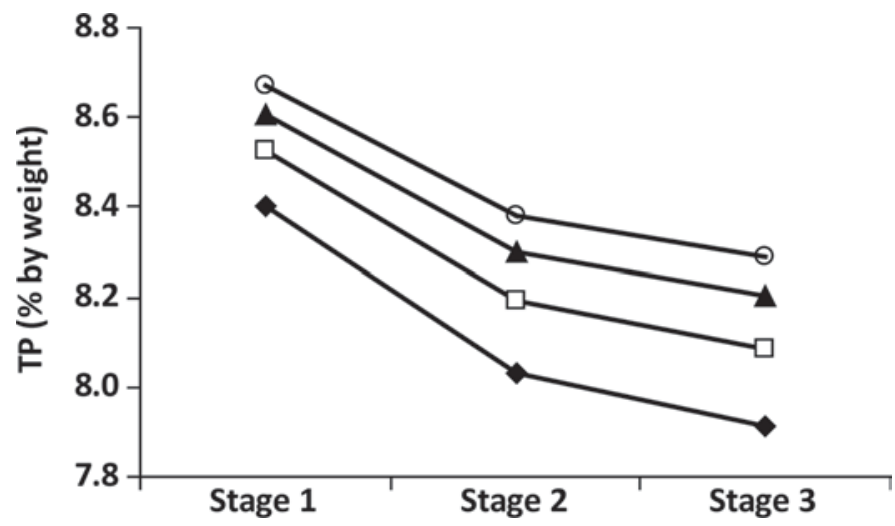

Figure 4. True protein (TP) in the retentate (\% by weight) in each stage of a 3 -stage microfiltration process with water diafiltration (stages 2 and 3), with increasing levels of $\mathrm{CN}$ as a percentage of TP (CN\%TP) because of heat denaturation of serum protein when starting with skim milk containing $3.2 \%$ TP and $81.97 \%$ CN\%TP. Model factors are from Table 1 and skim milk composition is from Table 3. : 81.97 CN\%TP; $\square: 83.75$ CN\%TP; $\mathbf{\Delta}: 85.00 \mathrm{CN} \% \mathrm{TP}$; ○: 85.94 $\mathrm{CN} \% \mathrm{TP}$.

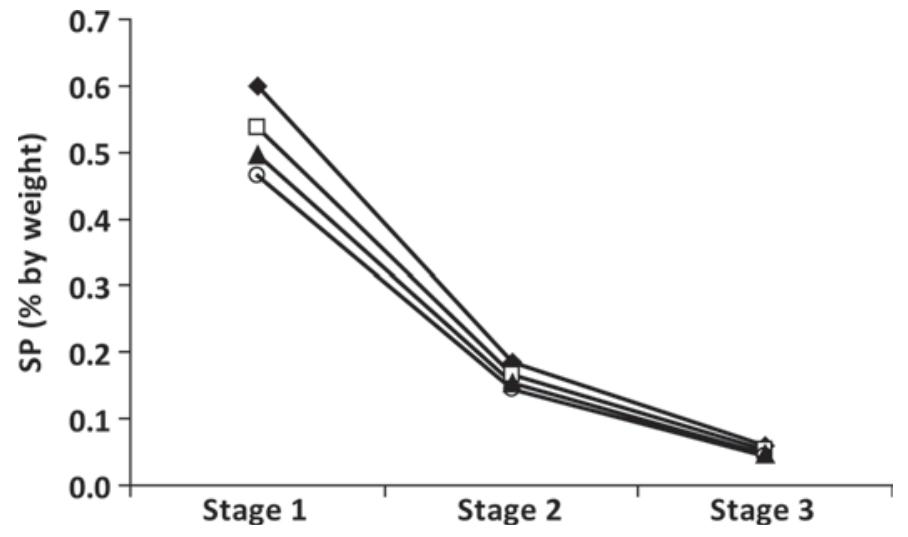

Figure 5. Serum protein (SP; \% by weight) in the permeate of each stage of a 3 -stage $3 \times$ microfiltration process with water diafiltration (stages 2 and 3), where $\mathrm{CN}$ as a percentage of true protein (CN\%TP) in the skim milk varied. Model factors are from Table 1 and skim milk composition is from Table 3. : 81.97 CN\%TP; $\square: 83.75$ CN\%TP; 85.00 CN\%TP; ○: $85.94 \mathrm{CN} \% \mathrm{TP}$.

Retentate. The increase in apparent $\mathrm{CN} \% \mathrm{TP}$ in skim milk caused by increased pasteurization temperature (Table 3) increased the TP content of the retentates produced by MF (Figure 4). Unlike the increase in TP content of MF retentate attributed to increased TP concentration in skim milk in Figure 1, the increase in $\mathrm{TP}$ concentration of the MF retentates was caused by increased retention of bound SP because of heat denaturation of SP and not increased $\mathrm{CN}$ content in the skim milk. Thus, the proportion of $\mathrm{CN}$ and $\mathrm{SP}$ contained in the retentates in Figures 1 and 4 would be different at the same TP concentration and their functionality may be different. Skim milk with increased apparent $\mathrm{CN} \% \mathrm{TP}$ attributed to heat denaturation of SP

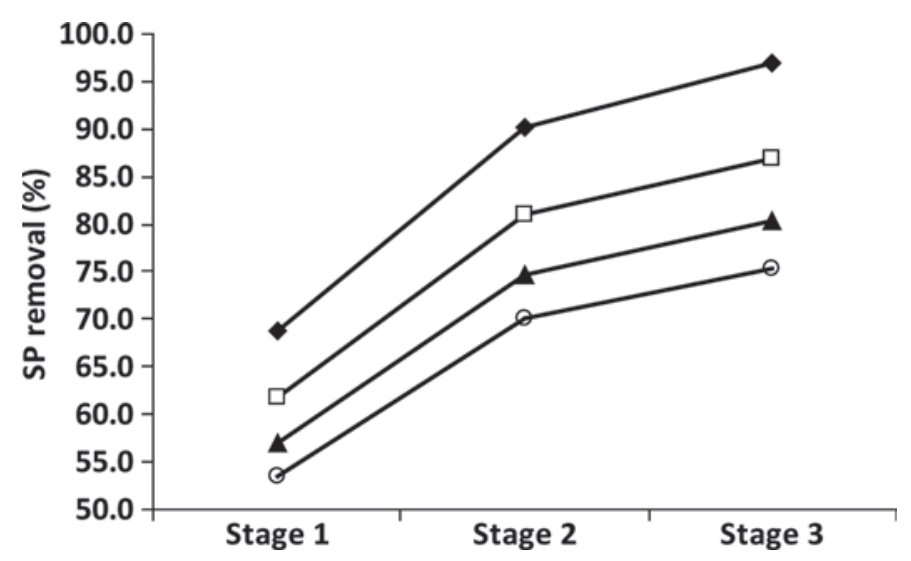

Figure 6. Cumulative serum protein (SP) removal (\%) for each stage of a 3 -stage $3 \times$ microfiltration process with water diafiltration (stages 2 and 3 ), where $\mathrm{CN}$ as a percentage of true protein $(\mathrm{CN} \% \mathrm{TP})$ in the skim milk varied. Model factors are from Table 1 and skim milk composition is from Table 3. : 81.97 CN\%TP; $\square$ : 83.75 CN\%TP; $\mathbf{\Delta}$ 85.00 CN\%TP; ○: $85.94 \mathrm{CN} \% \mathrm{TP}$. 
Table 9. Protein content of the third stage retentate, yield of liquid micellar CN concentrate (MCC) standardized to $9 \%$ true protein (TP) with a fourth stage finishing step, dry solids yield of milk serum protein isolate (MSPI), and total percentage serum protein (SP) removal for a 3-stage microfiltration process with water diafiltration (stages 2 and 3), with model factors from Table 1 and with different CN as a percentage of TP starting with $1,000 \mathrm{~kg}$ of the skim milks with the compositions from Table 3

\begin{tabular}{lcccc}
\hline & \multicolumn{3}{c}{ CN (\% TP in skim milk; Kjeldahl) } \\
\cline { 2 - 5 } Item & 81.97 & 83.75 & 85.00 & 85.94 \\
\hline Skim milk (kg) & 1,000 & 1,000 & 1,000 & 1,000 \\
Third stage TP (\% by weight) & 7.92 & 8.09 & 8.20 & 8.29 \\
Fourth stage permeate to remove (kg) & 40.22 & 34.00 & 29.67 & 26.40 \\
Yield liquid MCC, 9\% TP (kg) & 293 & 299 & 304 & 307 \\
Yield dry MSPI, 90\% (kg) & 6.24 & 5.62 & 5.19 & 4.86 \\
Total SP removal (\%) & 97.36 & 87.70 & 80.92 & 75.85 \\
\hline
\end{tabular}

produced third stage MF retentates with much higher levels $(0.05$ to $0.43 \%)$ of SP (Table 8 ) because some of the SP was bound to $\mathrm{CN}$ and could not be removed by $\mathrm{MF}$. The $\mathrm{CN} \% \mathrm{TP}$ in the retentates, not including the heat-denatured SP, decreased with increasing heat treatment (Table 8).

Permeate. The concentration of SP in the MF permeate decreased with increasing heat denaturation of $\mathrm{SP}$ and increased apparent $\mathrm{CN} \% \mathrm{TP}$ in the skim milk (Figure 5) because the concentration of SP in the permeate portion of the MF feed had decreased because an increasing amount of the SP was bound to CN. The decreased SP content of MF permeate was largest in the first stage of the MF system.

SP Removal. Cumulative SP removal decreased as heat treatment of the milk and $\mathrm{CN} \% \mathrm{TP}$ increased in the skim milk (Figure 6) because larger and larger amounts of SP were bound to $\mathrm{CN}$ and could not be removed from the skim milk by MF. The effect was very large, with the percentage SP removal in the final MCC decreasing from $97.36 \%$ to about $75.85 \%$ for apparent CN\%TP of 81.97 and $85.94 \%$, respectively (Table 9).

MCC and MSPI Yield. Increased apparent CN\%TP in skim milk caused by heat treatment led to an increased yield and changed protein composition of MCC but a decreased yield of MSPI when starting from the same skim milk (Table 9). When the apparent CN\%TP increased from 81.97 to $83.75 \%$, the MCC yield increased by approximately $2 \%$ but the MSPI yield decreased by about $10 \%$. When heat denaturation of SP increased, producing a change in $\mathrm{CN} \% \mathrm{TP}$ from 81.97 to $85.94 \%$, the decrease in yield of MSPI was about $22 \%$. Pasteurization time and temperature have very large effects on the yield of MSPI; therefore, it is important to minimize heat denaturation of SP before MF to maximize the economic performance of the process.

\section{Influence of Target Concentration Factor}

Retentate. When an MF milk fractionation process is being designed for a factory, the $\mathrm{CF}$ and DF factors under which the process will be operated may influence the efficiency of the process, the amount of membrane area required to process a particular volume of milk, and the composition of the products produced. As expected, the TP concentration in the MF retentates from each stage increased with increasing target CF (Figure 7). The large increase in protein and $\mathrm{CN}$ concentrations in both the final retentate (Table 10) and within each

Table 10. Composition of retentate (\% by weight) produced in the third stage of a microfiltration process (with water diafiltration after stage 1), with skim milk composition and component removal factors from Table 1 and different target concentration factors $(\mathrm{CF})$ and diafiltration factors (DF)

\begin{tabular}{lcccc}
\hline \multirow{2}{*}{$\begin{array}{l}\text { Milk } \\
\text { component }\end{array}$} & CF 2 + DF 2 & CF 3 + DF 3 & CF 4 + DF 4 & CF 5 + DF 5 \\
\cline { 2 - 5 } & 5.3768 & 7.9215 & 10.5186 & 13.1303 \\
True protein & 5.2460 & 7.8690 & 10.4920 & 13.1150 \\
CN & 0.1308 & 0.0525 & 0.0266 & 0.0153 \\
Serum protein & 0.0431 & 0.0173 & 0.0088 & 0.0050 \\
NPN & 97.57 & 99.34 & 99.75 & 0.88 \\
CN\% TP $^{1}$ & 1.0995 & 0.4417 & 0.2237 & 0.1285 \\
Lactose & 1.0146 & 1.4583 & 1.9246 & 2.3974 \\
Ash & & &
\end{tabular}

${ }^{1} \mathrm{CN} \% \mathrm{TP}=\mathrm{CN}$ as a percentage of true protein. 


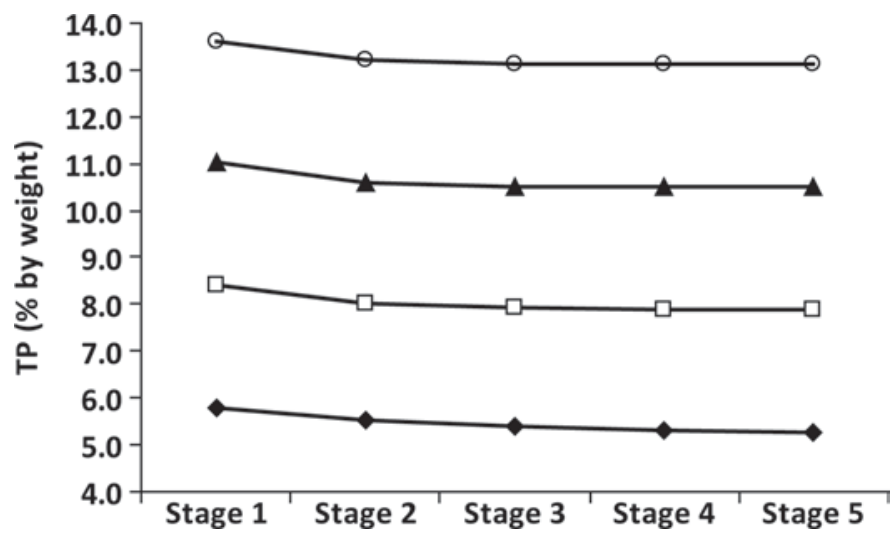

Figure 7. Effect of target microfiltration concentration factors $(\mathrm{CF})$ and diafiltration factors (DF) on true protein (TP) concentration of retentate in each stage of a 5-stage microfiltration process with water diafiltration at stage 2 and higher, with skim milk composition and component removal factors from Table 1. : CF $2+\mathrm{DF} 2$; $\square$ : $\mathrm{CF}$ $3+\mathrm{DF} 3 ; \boldsymbol{\Delta}: \mathrm{CF} 4+\mathrm{DF} 4 ; \mathrm{O}: \mathrm{CF} 5+\mathrm{DF} 5$.

stage (Table 7) as CF and DF factor increased would probably require a different design of the membrane modules (i.e., more open retentate flow channels and more energy for pumping) to cope with the higher protein concentrations in the retentates at $\mathrm{CF}$ of $4 \times$ and $5 \times$. As CF and DF increased, the third stage retentate had lower concentrations of SP, lactose, and NPN. Ash content of the third stage retentate increased when CF and DF were increased because most ash is bound to $\mathrm{CN}$ and $\mathrm{CN}$ concentration increased.

Permeate. The SP concentration in the MF permeate for the first stage was independent of $\mathrm{CF}$ (Figure 8 ) because the SP concentration in the permeate portion of the skim milk feed was the same for all CF.

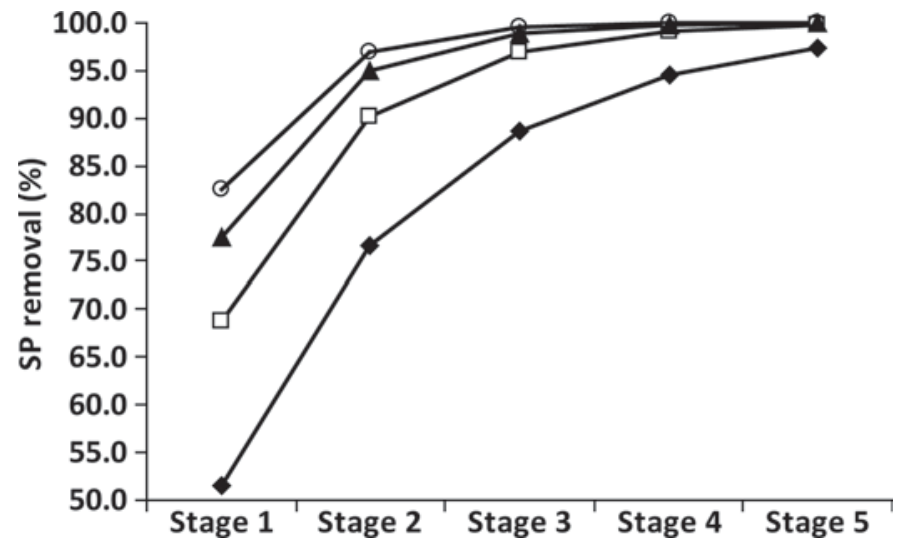

Figure 9. Effect of target concentration factors (CF) and diafiltration factors (DF) on cumulative serum protein (SP) removal for a 5 -stage microfiltration system with water diafiltration at stage 2 and higher, with skim milk composition and component removal factors from Table 1. : CF $2+$ DF 2; $\square$ : CF $3+$ DF 3; $\mathbf{\Delta}$ : CF $4+$ DF 4; $\mathrm{O}$ : CF $5+$ DF 5

However, the volume of permeate portion remaining in the retentate at the end of the first stage was lower with increasing CF. Therefore, when the retentate from the first stage was diluted back to the original volume of skim with water, there was a much lower SP concentration in the permeate from the second stage and the SP concentration in the permeate decreased with increasing CF. After the second stage, the difference in $\mathrm{SP}$ concentration in the permeate among the different concentration factors became smaller (Figure 8).

$S P$ Removal. Cumulative SP removal for each stage of the MF process increased as target $\mathrm{CF}$ and $\mathrm{DF}$ increased, with the greatest increase in removal occurring when $\mathrm{CF}$ and $\mathrm{DF}$ went from $2 \times$ to $3 \times($ Figure 9$)$. More

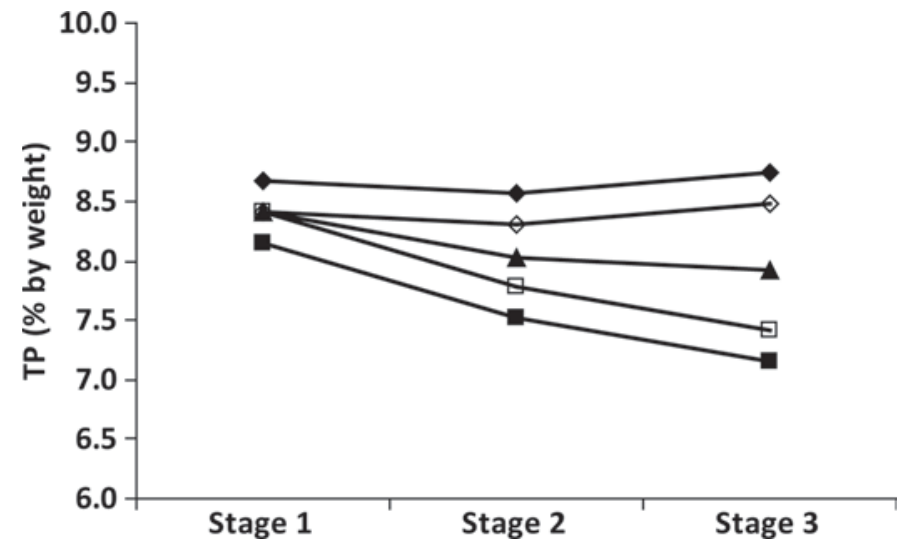

Figure 10. Effect of concentration factors (CF) and diafiltration factors (DF) on true protein (TP) concentration of retentate in each stage of a 3 -stage microfiltration process with water diafiltration (stages 2 and 3), with skim milk composition and component removal factors from Table 1. : CF 3.1 + DF 3.0; $\mathbf{\square}$ CF $2.9+$ DF 3.0; $\mathbf{\Lambda}$ : CF 3.0 + DF 3.0; $\diamond$ : CF $3.0+$ DF 2.9; $\square$ : CF $3.0+$ DF 3.1.
Figure 8. Effect of target concentration factors (CF) and diafiltration factors (DF) on serum protein (SP) concentration in the permeate for each stage of a 5 -stage microfiltration process with water diafiltration at stage 2 and higher, with skim milk composition and component removal factors from Table 1. : CF $2+$ DF 2; $\square$ : CF $3+$ DF 3; $\mathrm{CF} 4+\mathrm{DF} 4 ; \mathrm{O}: \mathrm{CF} 5+\mathrm{DF} 5$. 
Table 11. Composition of retentate (\% by weight) produced in the third stage of a microfiltration process, with skim milk composition and component removal factors from Table 1 and variable concentration factors $(\mathrm{CF})$ and diafiltration factors (DF) from Table 4

\begin{tabular}{lccccc}
\hline \multirow{5}{*}{$\begin{array}{l}\text { Milk } \\
\text { component }\end{array}$} & CF 3.0 + DF 3.0 & CF 3.1 + DF 3.0 & CF 2.9 + DF 3.0 & CF 3.0 + DF 3.1 & CF 3.0 + DF 2.9 \\
\cline { 2 - 6 } True protein & 7.9215 & 8.7340 & 7.1615 & 7.4190 & 8.4769 \\
CN & 7.8690 & 8.6824 & 7.1080 & 7.3695 & 8.4210 \\
Serum protein & 0.0525 & 0.0516 & 0.0534 & 0.0495 & 0.0558 \\
NPN & 0.0173 & 0.0170 & 0.0176 & 0.0163 & 0.0184 \\
CN\%TP & 99.34 & 99.41 & 99.25 & 99.33 & 99.34 \\
Lactose & 0.4417 & 0.4338 & 0.4492 & 0.4164 & 0.4691 \\
Ash & 1.4583 & 1.6062 & 1.3199 & 1.3658 & 1.5604 \\
\hline
\end{tabular}

${ }^{1} \mathrm{CN} \% \mathrm{TP}=\mathrm{CN}$ as a percentage of true protein.

$\mathrm{SP}$ was removed in 3 stages with a $\mathrm{CF}$ and $\mathrm{DF}$ of $3 \times$ than was removed in 5 stages with a $\mathrm{CF}$ and $\mathrm{DF}$ of $2 \times($ Figure 9$)$. The largest difference in percentage SP removal because of difference in $\mathrm{CF}$ was in the first stage, with about $82 \%$ SP removal in the first stage and greater than $95 \% \mathrm{SP}$ removal in 2 stages at a CF and $\mathrm{DF}$ of $5 \times$. This would be 1 less stage than running with a $\mathrm{CF}$ and $\mathrm{DF}$ of $3 \times$ to achieve at least a $95 \% \mathrm{SP}$ removal from skim milk. However, for each type of MF membrane, there will likely be a maximum concentration of $\mathrm{CN}$ in the retentate, above which would lead to rapid fouling of the membranes. Extensive membrane fouling that might occur at higher $\mathrm{CF}$ might also increase the rejection of SP by the membrane and reduce $\mathrm{SP}$ removal. This possible effect was not included in our theoretical calculations or in Figure 10.

\section{Influence of Control of Concentration and Diafiltration Factors}

Retentate. During normal operation of a multistage $\mathrm{MF}$ and diafiltration system, it is very difficult to control the $\mathrm{CF}$ and $\mathrm{DF}$ exactly in real time throughout the day. When the CF equaled the DF (i.e., a balanced scenario), the TP concentration of the MF retentates decreased gradually from stage to stage because SP was removed in the permeate (Figure 10). The balanced scenario is the same as the values for the $3.2 \% \mathrm{TP}$ in skim milk in Tables 2 and 5 and Figure 1. When the DF was less than the CF, then the TP concentration in the MF retentates increased compared with the balanced scenario (Figure 10); the opposite happened when DF was greater than CF (TP concentration decreased; Figure 10). There was a slightly larger effect of changing the CF than the DF because there was 1 more concentration than diafiltration step in the total 3 -stage process. If it was necessary to produce an MCC (i.e., final retentate) to a specific target $\mathrm{TP}$ or $\mathrm{CN}$ concentration, then accurate control of $\mathrm{CF}$ and $\mathrm{DF}$ would be necessary or a final finishing process step might be necessary to standardize MCC composition. The variation in components other than TP and $\mathrm{CN}$ in the final retentate was expected to be small (Table 11).

Permeate. The $\mathrm{CF}$ and DF in this range had a very small effect on the permeate composition from each stage (Table 12). These same variations had a large effect on retentate composition (Table 11).

SP Removal. When the CF was greater than the $\mathrm{DF}$, percentage SP removal increased compared with the balanced scenario, whereas SP removal decreased when $\mathrm{CF}$ was less than DF in comparison with the balanced scenario (Table 13). However, the effect of the differences in the balance of $\mathrm{CF}$ and $\mathrm{DF}$ on SP removal was very small compared with other factors.

MCC and MSPI Yield. The main affect of CF and $\mathrm{DF}$ on yield was on permeate removal required in the finishing stage (i.e., fourth stage) to produce an MCC with a $9 \%$ TP (Table 14). There was only a small effect on the yield of MSPI (Table 14).

\section{Influence of SP Removal Factors}

Differences in SP removal factors reflect a difference in resistance of the MF membrane to passage of SP through the membrane. In some cases this resistance may be attributed to inherent characteristics of the membrane, or resistance caused by foulant on the

Table 12. Effect of concentration factors $(\mathrm{CF})$ and diafiltration factors (DF) on serum protein concentration (\% by weight) in the permeate for each stage of a 3-stage microfiltration (MF) process, with skim milk composition and component removal factors from Table 1 and $\mathrm{CF}$ and DF from Table 4

\begin{tabular}{lccc}
\hline & \multicolumn{3}{c}{ Combination } \\
\cline { 2 - 4 } MF stage & CF 3.0 + DF 3.0 & CF 3.1 + DF 3.0 & CF 2.9 + DF 3.0 \\
\hline 1 & 0.599 & 0.599 & 0.599 \\
2 & 0.187 & 0.186 & 0.187 \\
3 & 0.058 & 0.058 & 0.059 \\
\hline
\end{tabular}


Table 13. Effect of concentration factors $(\mathrm{CF})$ and diafiltration factors (DF) on cumulative serum protein removal (\%) for a 3-stage microfiltration (MF) with skim milk composition and component removal factors from Table 1 and $\mathrm{CF}$ and DF from Table 4

\begin{tabular}{lccccc}
\hline & \multicolumn{5}{c}{ Combination } \\
\cline { 2 - 6 } MF stage & CF 3.0 + DF 3.0 & CF 3.1 + DF 3.0 & CF 2.9 + DF 3.0 & CF 3.0 + DF 3.1 & CF 3.0 + DF 2.9 \\
\hline 1 & 68.80 & 69.91 & 67.62 & 68.80 & 68.80 \\
2 & 90.27 & 90.97 & 89.49 & 90.25 & 90.29 \\
3 & 96.96 & 97.30 & 96.58 & 96.94 & 96.99 \\
\hline
\end{tabular}

membrane because of concentration polarization, or a combination of both. In the example provided below, 2 SP removal factors were used, 1 and 0.6 . A factor $<1$ indicates resistance to passage of SP. The removal factor of 1 is similar to reported performance (Zulewska, et. al., 2009) of a pilot-scale ceramic MF membrane when processing skim milk in a 3 -stage, $3 \times$ MF system at $50^{\circ} \mathrm{C}$ and the removal factor of 0.6 is similar to reported performance for a pilot-scale polymeric spiralwound MF system (Zulewska et al., 2009).

Retentate. As the membrane rejected more SP, the $\mathrm{TP}$ concentration in the MF retentate for each stage increased (Figure 11). The lactose, NPN, and ash contents of the third stage MF retentate were unchanged when SP removal factors changed (Table 15) because the removal factors for these components were assumed to be 1 . There is no information in the literature to indicate whether the removal factors for these components change when SP removal factor decreases. The $\mathrm{CN} \% \mathrm{TP}$ in the third stage retentate decreased as the removal factor decreased because SP concentration in the third stage MF retentate increased (Table 15).

Permeate. The concentration of SP in the permeate was higher in stages 2 and 3 of the MF process for the removal factor of 0.6 than for a removal factor of 1 (Figure 12) because with a removal factor of 1 a larger amount of SP was removed in the first stage. Therefore, the concentration was lower in the MF permeate of the second and third stages.

SP Removal. Cumulative percentage of SP removal increased as the SP removal factor increased (Figure
13). A membrane with a rejection factor of 0.8 would achieve approximately the same SP removal in 2 stages as would be achieved in 3 stages by a membrane with an SP removal factor of 0.6 (Figure 13). Heat denaturation of milk SP by pasteurization before MF had a similar effect on SP removal as operating an MF system with a lower SP removal factor. When apparent CN\% TP was $83.75 \%$ (Table 3), cumulative percentage SP removal after 3 stages was $86.94 \%$; this SP removal corresponds to an SP removal factor (caused by rejection of SP by the membrane) of between 0.7 and 0.8 for skim milk with a CN\% TP of $81.97 \%$.

MCC and MSPI Yield. The dry yield of MSPI decreased and the liquid MCC yield standardized to $9 \%$ TP increased as SP removal factors decreased because more of the SP was retained in the retentate (Table 16). This resulted in a decreasing $\mathrm{CN} \% \mathrm{TP}$ and increasing SP content of the final retentate (i.e., MCC) and may produce an MCC with different functionality than one with lower SP content (Table 15). Two MCC with the same CN\%TP, one caused by heat denaturationinduced binding of SP to CN micelles during pasteurization (Table 8) and one of the same CN\%TP caused by rejection of undenatured SP by the MF membrane (Table 15), may have different functionality even though their yields and compositions are the same.

\section{DISCUSSION}

The model used in this work made a variety of assumptions that may not hold true in all instances. Such

Table 14. Protein content of the third stage retentate, yield of liquid micellar CN concentrate (MCC) standardized to $9 \%$ true protein (TP) with a fourth stage finishing step, dry solids yield of milk serum protein isolate (MSPI), and total percentage serum protein (SP) removal for a 3-stage microfiltration process with water diafiltration (stages 2 and 3), with concentration factors (CF) and diafiltration factors (DF) from Table 4 , starting with $1,000 \mathrm{~kg}$ of $3.2 \%$ TP skim milk from Table 1

\begin{tabular}{|c|c|c|c|c|c|}
\hline Item & \multicolumn{5}{|c|}{ Combination } \\
\hline Third stage TP (\% by weight) & 7.92 & 8.73 & 7.16 & 7.42 & 8.48 \\
\hline Fourth stage permeate to remove $(\mathrm{kg})$ & 40.22 & 9.00 & 75.87 & 62.91 & 18.23 \\
\hline Yield liquid MCC, 9\% TP $(\mathrm{kg})$ & 293 & 293 & 293 & 293 & 293 \\
\hline Yield dry MSPI, 90\% (kg) & 6.24 & 6.24 & 6.24 & 6.25 & 6.23 \\
\hline
\end{tabular}




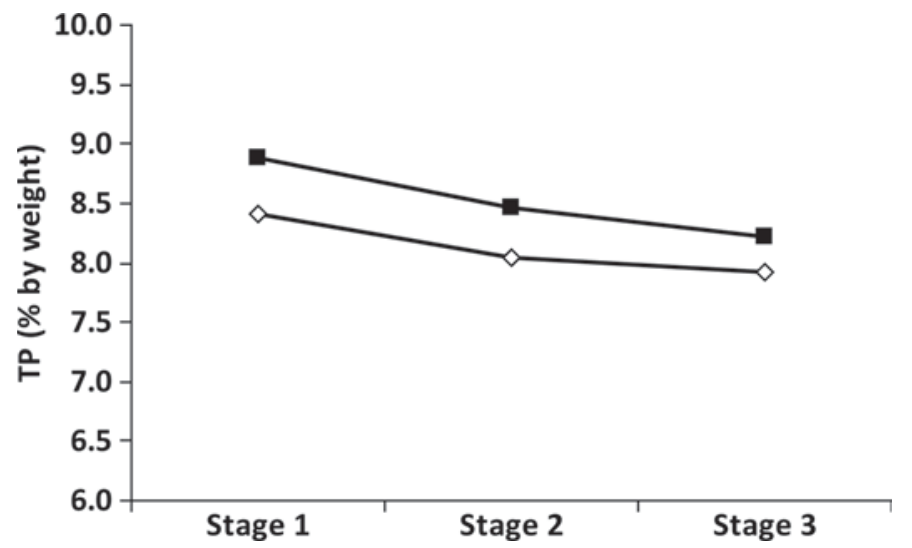

Figure 11. Effect of serum protein removal factor on true protein (TP) concentration in retentate of each stage of a 3-stage microfiltration process with water diafiltration (stages 2 and 3), with skim milk and concentration and diafiltration factors from Table $1 . \diamond$ : Removal factor 1 ; $\mathbf{\square}$ : removal factor 0.6 .

assumptions include a constant SP removal factor for the duration of each stage and $100 \%$ rejection of CN. It is likely that there could be instances where the SP removal factor would decrease during a run. If significant fouling occurred during running, then this could cause the SP removal factor to decrease with time during the run, producing a lower overall SP removal and yield of MSPI. This would most likely occur when the TP concentration in the retentate exceeded a critical value and concentration polarization driven membrane fouling and cake formation occurred. The second assumption, that $\mathrm{CN}$ is completely rejected by the membrane, is not absolute. Zulewska et al. (2009) found a very low level of $\mathrm{CN}$ in the permeate from the MF of skim milk using ceramic and spiral-wound membranes. However,

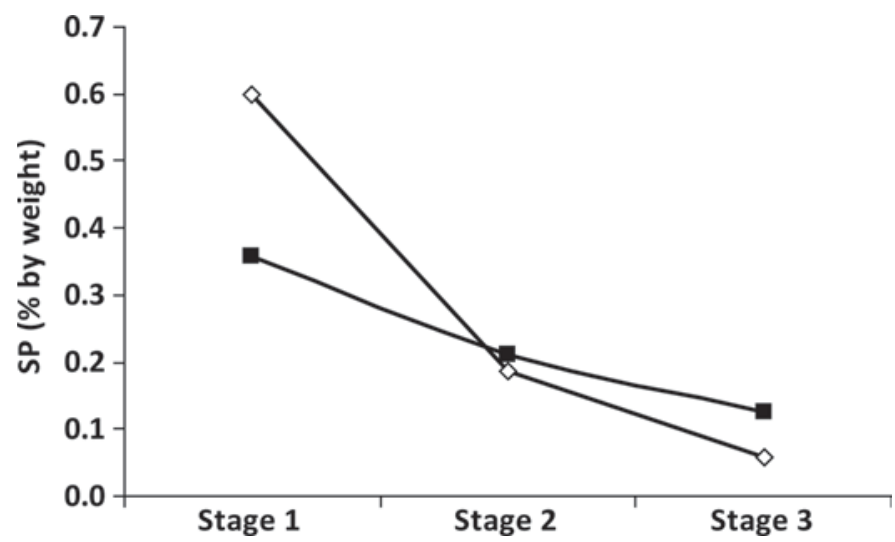

Figure 12. Effect of serum protein (SP) removal factors on SP composition (\% by weight) of permeate in each stage of a 3-stage microfiltration with water diafiltration (stages 2 and 3 ) process, with skim milk composition and concentration and diafiltration factors from Table 1. $\diamond$ : Removal factor 1 ; $\mathbf{\square}$ : removal factor 0.6 .
Table 15. Composition of retentate ( $\%$ by weight) produced in the third stage of a $3 \times$ microfiltration process with water diafiltration (stages 2 and 3), with different serum protein (SP) removal factors with skim milk composition from Table 1

\begin{tabular}{lcc}
\hline & \multicolumn{2}{c}{ SP removal factor } \\
\cline { 2 - 3 } Milk & 1 & 0.6 \\
\hline True protein & 7.9215 & 8.2194 \\
CN & 7.8690 & 7.8690 \\
SP & 0.0525 & 0.3504 \\
NPN & 0.0173 & 0.0173 \\
CN\% TP & 99.34 & 95.74 \\
Lactose & 0.4417 & 0.4417 \\
Ash & 1.4583 & 1.4583 \\
\hline
\end{tabular}

${ }^{1} \mathrm{CN} \% \mathrm{TP}=\mathrm{CN}$ as a percentage of true protein.

the amount of $\mathrm{CN}$ in the permeates is expected to be low, and thus the overall effect on yield would be low.

\section{CONCLUSIONS}

When skim milk TP concentration increased from 3.2 to $3.8 \%$, the TP concentration in the third stage retentate increased from 7.92 to $9.40 \%$, the yield of liquid MCC (9\% TP) from 1,000 kg of skim milk increased from 293 to $348 \mathrm{~kg}$, and the yield of dried MSPI (90\% SP) increased from 6.24 to $7.38 \mathrm{~kg}$. Increased heat treatment of skim milk $\left(72.9\right.$ to $\left.85.2^{\circ} \mathrm{C}\right)$ caused skim milk apparent CN\% TP as measured by Kjeldahl analysis to increase from 81.97 to $85.94 \%$ and the yield of MSPI decreased from 6.24 to $4.86 \mathrm{~kg}$, whereas the third stage cumulative percentage SP removal decreased from 96.96 to $70.08 \%$. A CF and DF of $2 \times$ gave a third stage retentate TP concentration of $5.38 \%$ compared with $13.13 \%$ for a CF and DF of $5 \times$, with the third

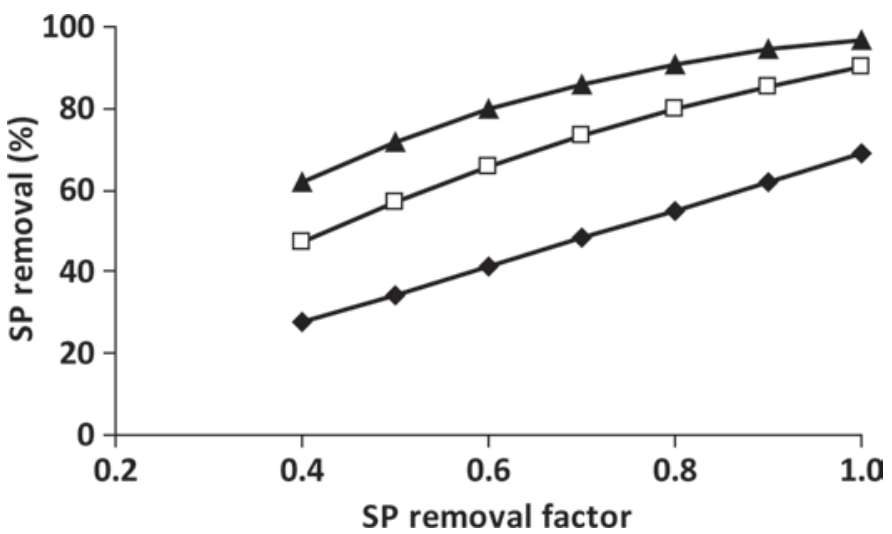

Figure 13. Effect of serum protein (SP) removal factor on cumulative SP removal for each stage of a 3-stage microfiltration process with water diafiltration (stages 2 and 3), with skim milk composition and concentration and diafiltration factors from Table 1 . $\bullet$ Stage $1 ; \square$ : stage $2 ; \boldsymbol{\Delta}$ : stage 3 . 
Table 16. Protein content of the third stage retentate, yield of liquid micellar CN concentrate (MCC) standardized to $9 \%$ true protein (TP) with a fourth stage finishing step, dry solids of milk serum protein isolate (MSPI), and total percentage serum protein (SP) removal for a 3-stage $3 \times$ microfiltration process with water diafiltration (stages 2 and 3), with different SP removal factors starting with 1,000 kg of skim milk with the composition from Table 1

\begin{tabular}{lcc}
\hline & \multicolumn{2}{c}{ SP removal factor } \\
\cline { 2 - 3 } Item & 1 & 0.6 \\
\hline Skim milk (kg) & 1,000 & 1,000 \\
Third stage TP (\% by weight) & 7.92 & 8.22 \\
Fourth stage permeate to remove (kg) & 40.22 & 29.67 \\
Yield liquid MCC, 9\% TP (kg) & 293 & 304 \\
Yield dry MSPI, 90\% (kg) & 6.24 & 5.19 \\
Total SP removal (\%) & 97.36 & 80.93 \\
\hline
\end{tabular}

stage cumulative SP removal increasing from 88.66 to 99.47\%. Variation in control of the balance between CF and DF (instead of an equal CF and DF) caused either a progressive increase or decrease in $\mathrm{TP}$ concentration in the retentate across stages, depending on whether $\mathrm{CF}$ was greater than DF (caused increasing TP in retentate) or $\mathrm{CF}$ was less than DF (caused decreasing $\mathrm{TP}$ in retentate). An increase in rejection of SP by the membrane from an SP removal factor of 1 to 0.6 caused a reduction in MSPI yield from 6.24 to $5.19 \mathrm{~kg} / 1,000$ $\mathrm{kg}$ of skim milk, and the third stage cumulative SP removal decreased from 96.96 to $79.74 \%$. Within the ranges of the 5 factors studied, the TP content of the third stage retentate was most strongly affected by the target $\mathrm{CF}$ and $\mathrm{DF}$ and variation in composition of skim milk. Cumulative percentage SP removal was most strongly affected by the heat treatment of skim milk, the SP removal factor, and the target $\mathrm{CF}$ and $\mathrm{DF}$. The MCC yield was most strongly affected by initial skim milk composition. The MSPI yield was also most strongly affected by composition of skim milk, whereas the heat treatment of milk and SP removal factor also had large effects.

\section{ACKNOWLEDGMENTS}

The authors thank the New York State Milk Promotion Board (Albany, NY) and the Northeast Dairy Foods Research Center (Ithaca, NY) for partial funding of this research. The technical assistance of Tom Burke, Maureen Chapman, Mark Newbold, Jessica Mallozzi, and Karen Wojciechowski from the Department of Food Science at Cornell University (Ithaca, NY) and the staff of the Cornell Dairy Plant was greatly appreciated.

\section{REFERENCES}

AOAC. 2000. Official Methods of Analysis. 17th ed. Association of Official Analytical Chemists, Gaithersburg, MD.

Barbano, D. M. 1990. Seasonal and regional variation in milk composition in the US. Pages 96-105 in Proc. 1990 Cornell Nutrition Conference. Cornell University, Ithaca, NY.

Britten, M., and Y. Pouliot. 1996. Characterization of whey protein isolate obtained from milk microfiltration permeate. Lait 76:255265.

Jenness, R. 1959. Milk salts. Pages $158-181$ in Principles of Dairy Chemistry. S. Patton, ed. John Wiley and Sons Inc., New York, NY.

Kaylegian, K. E., J. M. Lynch, G. E. Houghton, J. R. Fleming, and D. M. Barbano. 2006. Modified versus producer milk calibration: Mid-infrared analyzer performance validation . J. Dairy Sci. 89:2833-2845.

Laben, R. C. 1963. Factors responsible for variation in milk composition. J. Dairy Sci. 46:1293-1301.

Lynch, J. M., D. M. Barbano, and J. R. Fleming. 1998. Indirect and direct determination of the casein content of milk by Kjeldahl nitrogen analysis: Collaborative study. J. AOAC Int. 81:763-774.

Ma, Y., and D. M. Barbano. 2003. Milk pH as a function of $\mathrm{CO}_{2}$ concentration, temperature and pressure in a heat exchanger. J. Dairy Sci. 86:3822-3830.

Ma, Y., C. Ryan, D. M. Barbano, D. M. Galton, M. A. Rudan, and K. J. Boor. 2000. Effect of somatic cell count on quality and shelf-life of pasteurized fluid milk. J. Dairy Sci. 83:264-274.

Nelson, B. K., and D. M. Barbano. 2005. A microfiltration process to maximize removal of serum proteins from skim milk before cheese making. J. Dairy Sci. 88:1891-1900.

Papadatos, A., M. Neocleous, A. M. Berger, and D. M. Barbano. 2003. Economic feasibility evaluation of microfiltration of milk prior to cheesemaking. J. Dairy Sci. 86:1564-1577.

Papadatos, A., A. M. Berger, J. E. Pratt, and D. M. Barbano. 2002. A nonlinear programming optimization model to maximize net revenue in cheese manufacture. J. Dairy Sci. 85:2768-2785.

Quiñones, H. J., D. M. Barbano, and L. G. Phillips. 1997. Influence of protein standardization by ultrafiltration on the viscosity, color, and sensory properties of skim and $1 \%$ milk. J. Dairy Sci. 80:3142-3151.

Quiñones, H. J., D. M. Barbano, and L. G. Phillips. 1998. Influence of protein standardization on the viscosity, color, and sensory properties of $2 \%$ and $3.3 \%$ fat milks. J. Dairy Sci. 81:884-894.

Rowland, S. J. 1937. The soluble protein fraction of milk. J. Dairy Res. 8:6-14.

Sawyer, W. H. 1969. Complex between $\beta$-lactoglobulin and $\kappa$-casein. A review. J. Dairy Sci. 52:1347-1355.

Vadi, P. K., and S. S. H. Rizvi. 2001. Experimental evaluation of a uniform transmembrane pressure crossflow microfiltration unit for the concentration of micellar casein from skim milk. J. Membr. Sci. 189:69-82.

Zulewska, J., M. Newbold, and D. M. Barbano. 2009. Efficiency of serum protein removal from skim milk with ceramic and polymeric membranes at $50^{\circ} \mathrm{C}$. J. Dairy Sci. 92:1361-1377. 